\title{
The failure analysis and lifetime prediction for the solder joint of the magnetic head
}

\author{
Xianghui Xiao $\cdot$ Minfang Peng $\cdot$ Jaime S. Cardoso $•$ \\ Rongjun Tang $\cdot$ YingLiang Zhou
}

Received: 29 May 2014/ Accepted: 11 September 2014/Published online: 27 September 2014

(C) Springer-Verlag Berlin Heidelberg 2014

\begin{abstract}
Micro-solder joint (MSJ) lifetime prediction methodology and failure analysis (FA) are to assess reliability by fatigue model with a series of theoretical calculations, numerical simulation and experimental method. Due to shortened time of solder joints on high-temperature, high-frequency sampling error that is not allowed in productions may exist in various models, including round-off error. Combining intermetallic compound (IMC) growth theory and the FA technology for the magnetic head in actual production, this thesis puts forward a new growth model to predict life expectancy for solder joint of the magnetic head. And the impact of IMC, generating from interface reaction between slider (magnetic head, usually be called slider) and bonding pad, on mechanical performance during aging process is analyzed in it. By further researching on FA of solder ball bonding, thesis chooses AuSn4 growth model that affects least to solder joint mechanical property to indicate that the IMC methodology is suitable to forecast the solder lifetime. And the diffusion constant under work condition $60{ }^{\circ} \mathrm{C}$ is 0.015354 ; the solder lifetime $\mathrm{t}$ is 14.46 years.
\end{abstract}

\footnotetext{
X. Xiao $(\varangle) \cdot$ M. Peng $(\square)$

Institute of Electrical and Information Engineering,

Hunan University, Changsha 410082, China

e-mail: xiaoen3@126.com

M. Peng

e-mail: pengminfang@hnu.edu.cn

J. S. Cardoso

INESC Porto and Faculty of Engineering, University of Porto, 4099-002 Porto, Portuguese Republic

R. Tang · Y. Zhou

Japan's TDK Groups, Dongguan 523000, China
}

\section{Introduction}

There are two basic ways in micro-solder joint (MSJ) lifetime prediction methodology: one associating life expectancy of solder joints with inelastic deformation variation and the other associating it with deformation energy density.

Fatigue damage is one of the main kinds in electronic packaging damage. We can find a lot to refer to in forecasting lifetime of solder joints based on fatigue model.

Wiese et al. [1] studied the creep behavior of bulk, PCB sample, and Flip Chip solder joint samples of $\mathrm{Sn} 4.0 \mathrm{Ag} 0.5 \mathrm{Cu}$ solder and identified two mechanisms for steady state creep deformation for the bulk and PCB samples. They attributed these to climb controlled (low stress) and combined glide/climb (high stress) behavior and represented steady state creep behavior using double power law model.

Schubert et al. [2] combined data from different sources and from their own testing on different compositions of $\mathrm{SnAgCu}$ solder $(\mathrm{Sn} 3.8 \mathrm{Ag} 0.7 \mathrm{Cu}, \quad \mathrm{Sn} 3.5 \mathrm{Ag} 0.75 \mathrm{Cu}$, $\mathrm{Sn} 3.5 \mathrm{Ag} 0.5 \mathrm{Cu}$, and $\mathrm{Castin}^{\mathrm{TM}}$ ). They also identified two regions for stress-strain rate behavior, but postulated the high-stress region as power law break-down region, and chose hyperbolic sine function to represent creep data.

Keke et al. [3] generated their data on single-lap shear specimen of $\mathrm{Sn} 3.9 \mathrm{Ag} 0.6 \mathrm{Cu}$ solder alloy. She also modeled the steady state creep behavior using hyperbolic sine function postulating power law break-down at high values of stress.

Finally, Morris et al. used a double power law constitutive model to represent creep data on single-lap shear specimens of $\mathrm{Sn} 3.0 \mathrm{Ag} 0.5 \mathrm{Cu}$ solder joints. The stress exponents of 6.6 and 10.7 were suggested for the low- and high-stress regions. 
It can be seen that the solder of $\mathrm{SBB}$ is $\mathrm{SnAgCu}$ which is the best alternative for eutectic $\mathrm{Sn} / \mathrm{Pb}$ solder. So the solder ball lifetime prediction is very important. It is a criterion of production quality also can direct production. In fact, there is not a suitable methodology of SBB lifetime prediction [4-8].

This subject mainly focuses on $\mathrm{SnAgCu}$ model and mainly studies the methodology of SBB lifetime prediction in magnetic head based on intermetallic compound (IMC) growth kinetics and accumulate creep strain and energy density theory.

There are three new ideas brought forth by this paper. Firstly, it applies IMC analysis to research on head's liability and lifespan. Secondly, by research on FA of products, it discusses on generating of IMC and impact on liability of the solder joint. Thirdly, it presents an improved IMC growth model that can be applied to forecast of solder joints lifespan.

\section{SBB of magnetic head failure analysis}

\subsection{SBB working procedure}

SBB working procedure is shown in Fig. 1 below.

We can see that the occurrence of SBB is along with the laser energy.

\subsection{Investigation of $\mathrm{Au}$ and $\mathrm{Sn}$ alloy combination}

For the best result of $\mathrm{Au}$ and $\mathrm{Sn}$ alloy combination, this paper will expound on following three conditions: X-section (normally do SEM before) on each pad of the magnetic head (Experiment 1) and de-wetting (Experiment 2). We usually take it as a visual one with its normal condition which is just in normal pressure and temperature), and hot air gun (Experiment 3). Usually in the AuSn compound, when the gold layer is less, or the consumption is finishing, the $\mathrm{Sn}$ will generate CuSn compounds with the gold. In other words, Snx is AuSnx, Sn2 is AuSn2, and Sn4 is AuSn4. They can present different microstructure in SEM. EDX (energy dispersive X-ray detector) can be used to determine AuSn2 or AuSn4.

Let us pick two groups of heads as samples in Models 1 and 2 .

In Model 1, Sn will directly compound with $\mathrm{Ta} / \mathrm{Ni}$, the adhesive layer between $\mathrm{Al} / \mathrm{Cu}$ and $\mathrm{Sn}$, under a high energy/ temp circumstance, which would lead to a poor connection. In Model 2, Au diffusion/reaction with Sn leads to an $\mathrm{AuSn}_{\mathrm{x}}$ growth and an Au migration. Normally, the IMC will be increased at very low speed, while under a high temperature, the diffusion rate will accelerate largely. Here we use $\mathrm{Sn}_{\mathrm{x}}$ for a further comparison on $\mathrm{x}$ in the following writings (Fig. 2).

Taking SEM to return to crack sample under a $5-55^{\circ} \mathrm{C}$, ORT sample (temp from 5 to $55^{\circ} \mathrm{C}$ ) was found to be cracked at solder pad, as shown in Fig. 3 below.

Proceeding X-section to failure products on one pad, we see an obvious bubble between solder/pad, as shown in Fig. 4, and that no $\mathrm{Cu}$ in solder residue $(\mathrm{Sn})$ indicates a $\mathrm{Ta} /$ $\mathrm{Ni}$ de-wetting curried.

Proceeding hot air gun implementation to two sets of heads under $125^{\circ} \mathrm{C}$ for $1 \mathrm{~min}$, we found an obvious dewetting on thinner $\mathrm{Au} / \mathrm{Ta} / \mathrm{Cu}$ pad. And thinner $\mathrm{Cu}$ would easily diffuse and leads to $\mathrm{Cu} / \mathrm{Ta}$ encounter which is shown in Fig. 5.

After changing pad configuration, we can see that we already have the similar structure on suspension $\mathrm{Cu} / \mathrm{Ni}$ / thinner and get the positive result, but do not know the $\mathrm{Ta} /$ $\mathrm{Ni}$ status if we add $\mathrm{Ta}$ layer. If $\mathrm{Ta} / \mathrm{Ni}$ connection is not

Fig. 1 SBB working procedure

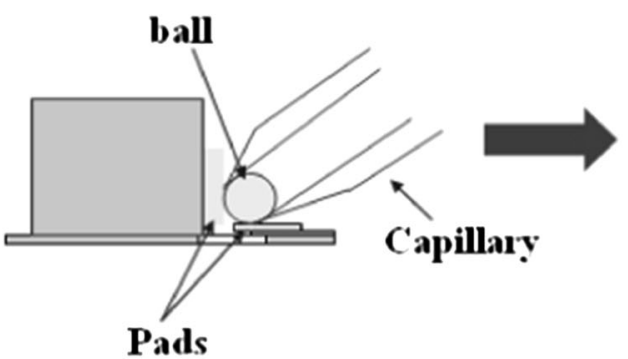

Ball positioning hold by capillary

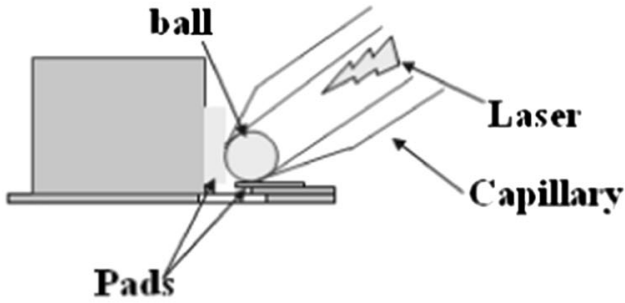

Laser reflow

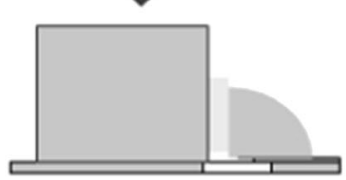


Fig. 2 SBB joint failure model

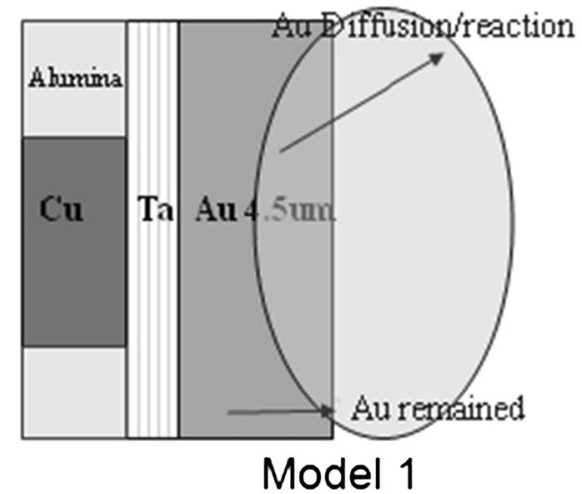

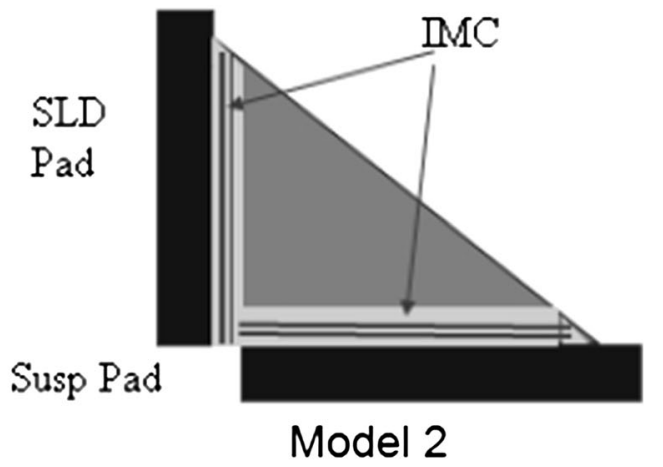

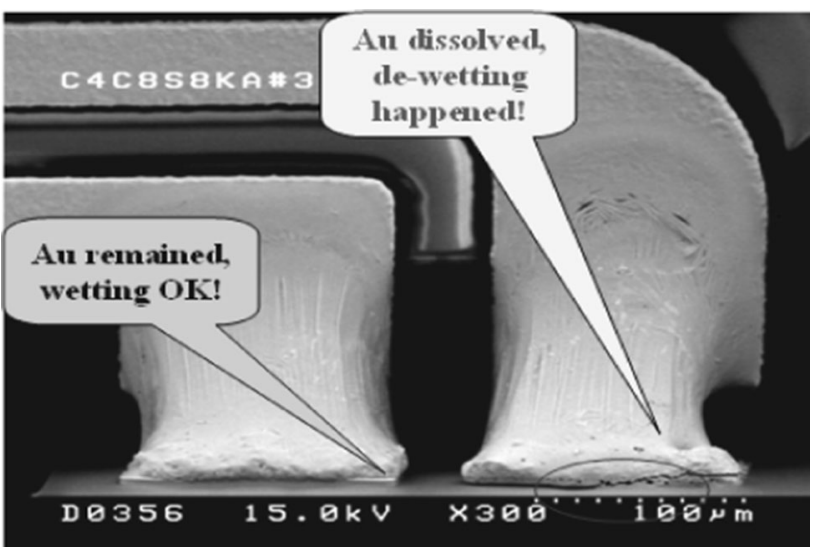

Fig. 3 Returned crack sample

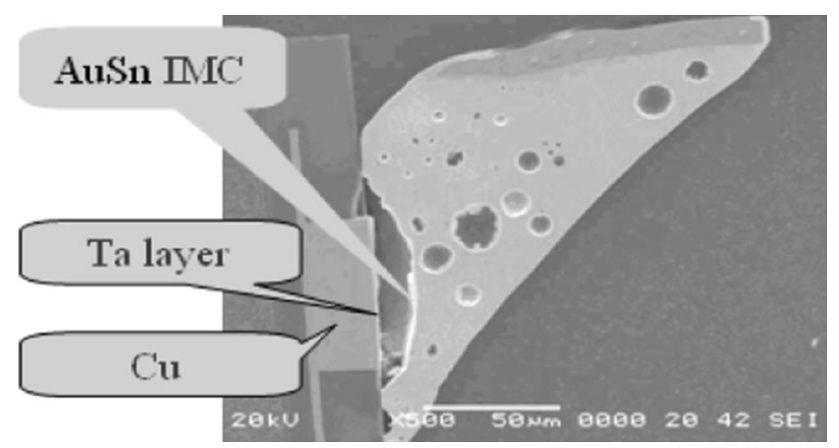

Fig. 4 X-section on one pad

good, the $\mathrm{Cu} / \mathrm{Ni}$ complete separation model is an improved model only increase $\mathrm{Cu}$ area.

Through making comparison of the different alloy combinations of Au and Sn, investigating the solder joints' infiltration percentages [wetting (\%)] according to the SEM results and the SBB bubble-free rates [SBB (\%)] according to the after-grinding statistical results, the best SBB optimized condition and the best combination (the Snx mentioned above) are shown in Table 1.

In Table 1, Snx represents AuSnx, $\mathrm{Sn}_{2}$ is $\mathrm{AuSn}_{2}, \mathrm{Sn}_{4}$ is $\mathrm{AuSn}_{4}$, and they can present different microstructure in SEM. $\mathrm{AuSn}_{2}$ and $\mathrm{AuSn}_{4}$ can be distinguished by using EDX (energy dispersive X-ray detector) [9].

It is concluded that if temp/energy is high, Au should be diffused entirely and de-wetting occurs. And if temp/ energy is not sufficient, SBB yield should be poor. Considering margin and SBB yield, Group 5 is adopted.

After a comparison among these three experiments, we found too much time is consumed in Exp 1 and some failures cannot be detected in Exp 2, while results can be quickly and easily judged in Exp 3. And we can get the following conclusion: Resistance is changed or crack is caused by IMC layer expansion; low temp/energy could not bond entirely. And at high temp/energy would occur de-wetting; Void will be formed due to Au diffusion, it will migrate gradually to $\mathrm{Sn}$ side; Growth ability and liability of $\mathrm{AuSn}_{4}$ are better than those of $\mathrm{AuSn}_{2}$.

\section{The improved IMC growth model}

The effects of solder alloy composition on microstructure, especially the formation of large IMCs, are very important. IMC $[10,11]$ is a key issue affecting the integrity and reliability of solder joints.

After solidification of a solder joint is completed, the process of intermetallic growth does not end. For a given solder alloy and base material, the growth is related to time and temperature. In fact, a satisfactory result can be obtained by this growth model under some circumstance; however, that error still exists makes simulated result sequence unmatched with the standard database. Bringing $C_{\text {offset }}$ and $t_{\text {factor, }}$, this paper issues an iterative error correction to improve IMC growth model and received a satisfactory result in predicting solder joint lifespan. 
Fig. 5 Bonding pad qualification
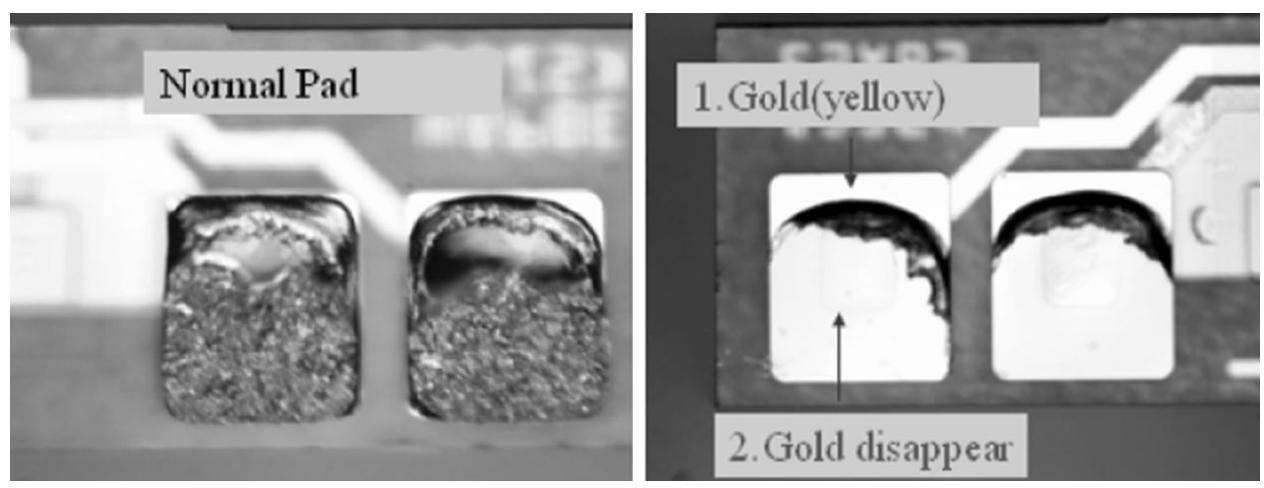

Table 1 SBB condition optimization result

\begin{tabular}{llll}
\hline $\mathrm{Sn}_{2}$ & Group 1 & Group 2 & Group 3 \\
\hline Voltage (V) & 270 & 270 & 260 \\
Time (ms) & 3.5 & 4.1 & 6.1 \\
Energy (mJ) & $36-41$ & $41-45$ & $51-55$ \\
Wetting (\%) & 96 & 87 & 79 \\
SBB (\%) & 66.7 & 85.7 & 93.7 \\
\hline Sn 4 & Group 4 & Group 5 & Group 6 \\
\hline Voltage (V) & 260 & 260 & 260 \\
Time (ms) & 5.1 & 4.5 & 4.1 \\
Energy (mJ) & $42-48$ & $38-45$ & $39-41$ \\
Wetting (\%) & 100 & 100 & 100 \\
SBB (\%) & 97.1 & 94.3 & 88.2 \\
\hline
\end{tabular}

The improved growth model is a diffusion-controlled process and can be represented by the following growth model:

$$
\begin{aligned}
x & =x_{0}+x_{\mathrm{R}}(t)-\mathrm{C}_{\text {offset }} \\
& =x_{0}+\sqrt{D t}-\mathrm{C}_{\text {offset }}
\end{aligned}
$$

where $x$ is the layer thickness (mm) at time, $t(\mathrm{~s})$;

$x_{0}$ is the initial layer thickness $(\mathrm{mm})$;

$t$ is the time;

$D$ is a constant (units of mm-s-n);

$C_{\text {offset }}$ is the offset constant.

Let us conduct an error correction to results of (1) above.

Provided that sequence of acquired result was $x_{R}$ which comes from (1), target sequence $y_{T}$, the Euclidean distance was (2),

$d^{2}=\sum_{t=0}^{N-1}\left[\left(x_{0}+x_{R}(t)-C_{\text {offset }}\right)-y_{T}(t)\right]^{2}$

We can take $x_{R}(t)$ and $y_{T}(t)$ as a function of $C_{\text {offset }}$ shown as (3).
$f(c)=d^{2}=\sum_{t=0}^{N-1}\left[\left(x_{0}+x_{R}(t)-C_{\text {offset }}\right)-y_{T}(t)\right]^{2}$

Taking $C_{\text {offset }}$ derivation of (5) and making it to zero, we get (6)

$$
\begin{gathered}
f^{\prime}(c)=2 \sum_{t=0}^{N-1}\left[\left(x_{0}+x_{R}(t)-C_{\text {offset }}\right)-y_{T}(t)\right] \cdot(-1)=0 \\
C_{\text {offset }}=\frac{1}{N}\left[\sum_{t=0}^{N-1}\left(x_{0}+x_{R}(t)\right)-\sum_{i=0}^{N-1} y_{T}(t)\right]=R_{f}-T_{f}
\end{gathered}
$$

Defining $t_{\text {factor: }}$

$t_{\text {factor }}=R_{f} / T_{f}$

Providing the sequence $T(n) n=0,1, \ldots, Q_{T E n d}$ of one estimated value, the result sequence $R(i) k=0,1, \ldots, Q_{R E n d}, \quad$ interval time $\Delta_{T} t, \Delta_{R} t, \Delta_{T \text { - }}$ $t \neq \Delta_{R} t$ and $Q_{R E n d} \geq Q_{\text {TEnd }}$ are obtained. The iterative error correction proposed in this paper is showed below:

1. Initialization $C_{\text {offset }}^{0} t_{\text {factor }}^{0}$ on the basis of (4), (5), the corresponding initialized time sequence of the two sequences is

$$
\begin{aligned}
& T_{T}^{0}=\left(0: \mathrm{Q}_{\text {TEnd }}-1\right) \times \Delta_{T} t \\
& T_{R}^{0}=\left(0: \mathrm{Q}_{\text {REnd }}-1\right) \times \Delta_{R} t
\end{aligned}
$$

2. As to the Loop $N$, update interval time and time sequence on the basis of (8)

$$
\begin{aligned}
& \Delta_{T} t^{n+1}=t_{\text {factor }}^{n} \times \Delta_{T} t^{n} \\
& T_{T}^{n+1}=T_{T}^{n} \times \Delta_{T} t^{n+1}
\end{aligned}
$$

3. Search in $T_{R}^{0}$ the first subscript $n$ Index that is bigger than the end element of $T_{T}^{n}$.

$T_{R}^{0}(\mathrm{n})>T_{T}^{n}$

At this point, we can end the correction. If the number of operations has been to a pre-specified number $N$, the methods above are of failure. Otherwise we 
can use $Q_{1}, T_{R}^{1}, T_{T}^{1}$ to replace $Q_{0}, T_{R}^{0}, T_{T}^{0}$ and continue "(2)" to operate.

4. Calculate $C_{\text {offset }}^{n+1}$, minus $C_{\text {offset }}^{n+1}$ from $R^{i+1}$ and update $t_{\text {factor }}^{n+1}$.

5. Repeat steps (2)-(4) until the condition is met.

After correction, $T^{\text {final }}$ and $R^{\text {final }}$ are obtained. We can judge similarity between $T(\mathrm{n})$ and $R(k)$ based on the closeness of these two sequences. If $C_{\text {offset }}=0$, we can consider this result is the best one. So from Fig. 6, we can get the diffusion constant under work condition $60{ }^{\circ} \mathrm{C}$ is 0.015354, the maximum $\mathrm{AuSn}_{4}$ thickness is $0.025 \mathrm{~nm}$, and the thickness of $\mathrm{AuSn}_{4}$ growth is $0.2 \mathrm{~nm}$. From the equation $x=x_{0}+x_{\mathrm{R}}(t)-\mathrm{C}_{\text {offset }}$ we can get that the solder lifetime $\mathrm{t}$ is 14.46 years

\section{The preliminary result of prediction methodology}

IMC growths are influenced by many factors, mainly for low temperature grain boundary diffusion and solder joint intergranular diffusion. This thesis reviewed on impact of high temperature aging in IMC formation. In fact, solder joint works only under low temperature below $100{ }^{\circ} \mathrm{C}$. Higher the temperature, faster the IMC formation growth and higher the failure rate of solder joint. IMC formation is required for MSJ. However, it affects SBB reliability. Too thick of it may cause the loss of solder joint mechanical shock resistance while to this may cause a problem in reliability. Take 100,115 and $140{ }^{\circ} \mathrm{C}$ working condition for instance, when the general current is $31.6 \mathrm{~mA}$, resistance did not vary much, as shown in Fig. 6, which led to no further probing.

Namely IMC growth is a function of time and temperature is established. With prolonged time and increased temperature, it becomes thick and fragile. By data and figures, solder joint failure led to heading failure and that inevitably led to the whole disk failure. While the life span of most electronics is more than 5 years, this requires the engineer to pay attention to avoid the above situation (Fig. 7).

\section{Comparison with other methods}

The prediction methodology for solder mainly includes electromigration prediction and thermal fatigue life prediction [12, 13].

The normal IMC algorithm can be represented by the following growth model:

$x=x_{0}+\sqrt{D t}$

where $x$ is the layer thickness $(\mathrm{mm})$ at time, $t(s) ; x_{0}$ is the
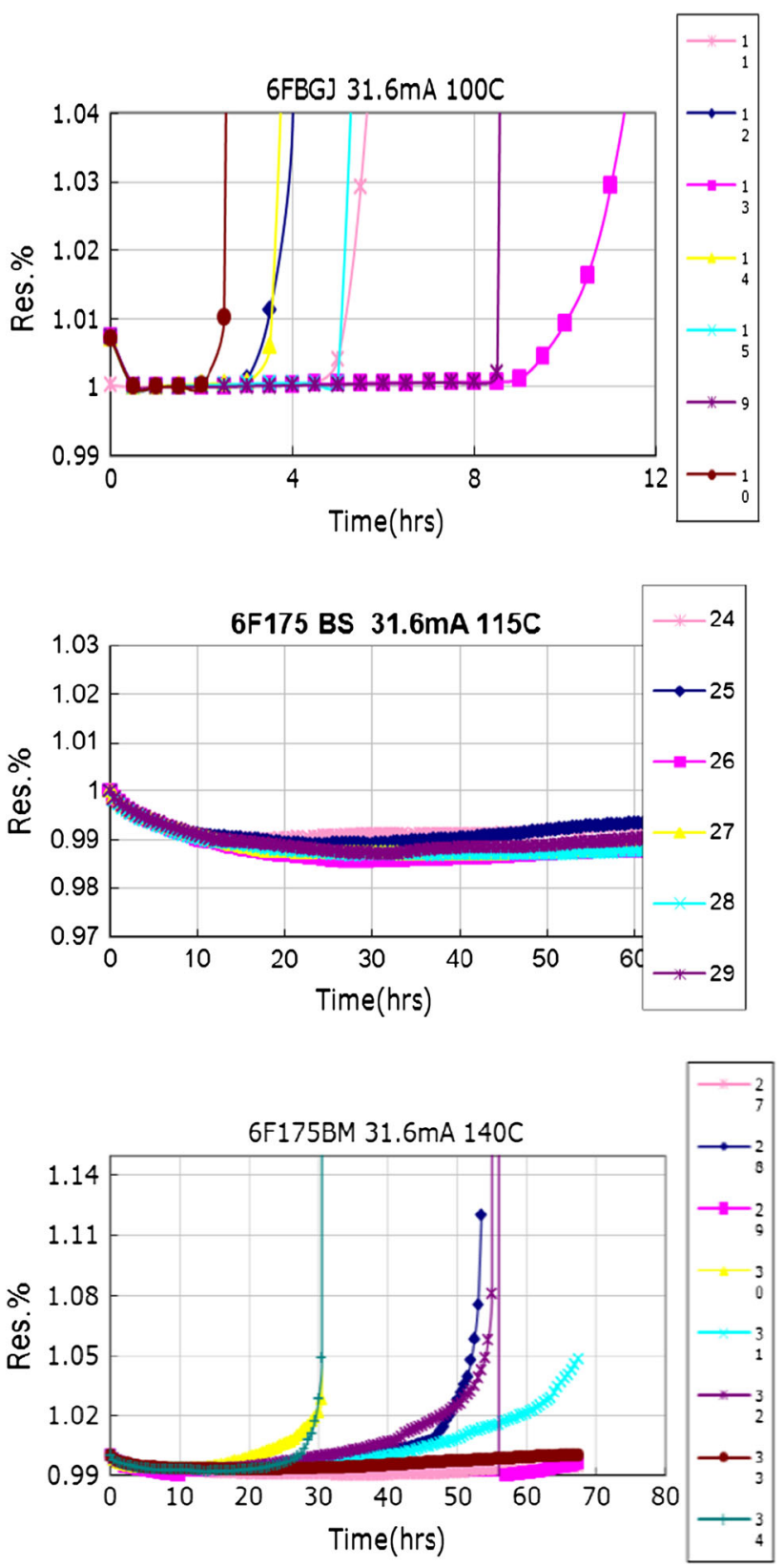

Fig. 6 Relationship between the solder joint failure rate and aging time

initial layer thickness (mm), $t$ is the time; $D$ is a constant (units of mm-s-n).

$D=D_{0} e^{(-Q / R T)}$

where $D_{0}$ is the diffusion constant (units of mm-s-n) at T $(\mathrm{K}) ; Q$ is the activation energy $(\mathrm{J} / \mathrm{mol}) ; R$ is the universal gas constant $(8.314 \mathrm{~J} / \mathrm{mol} \mathrm{K}) ; \mathrm{T}$ is the absolute temperature $(K)$.

The data were analyzed by a multivariable, linear regression analysis of (1), (2) placed in the following format: 

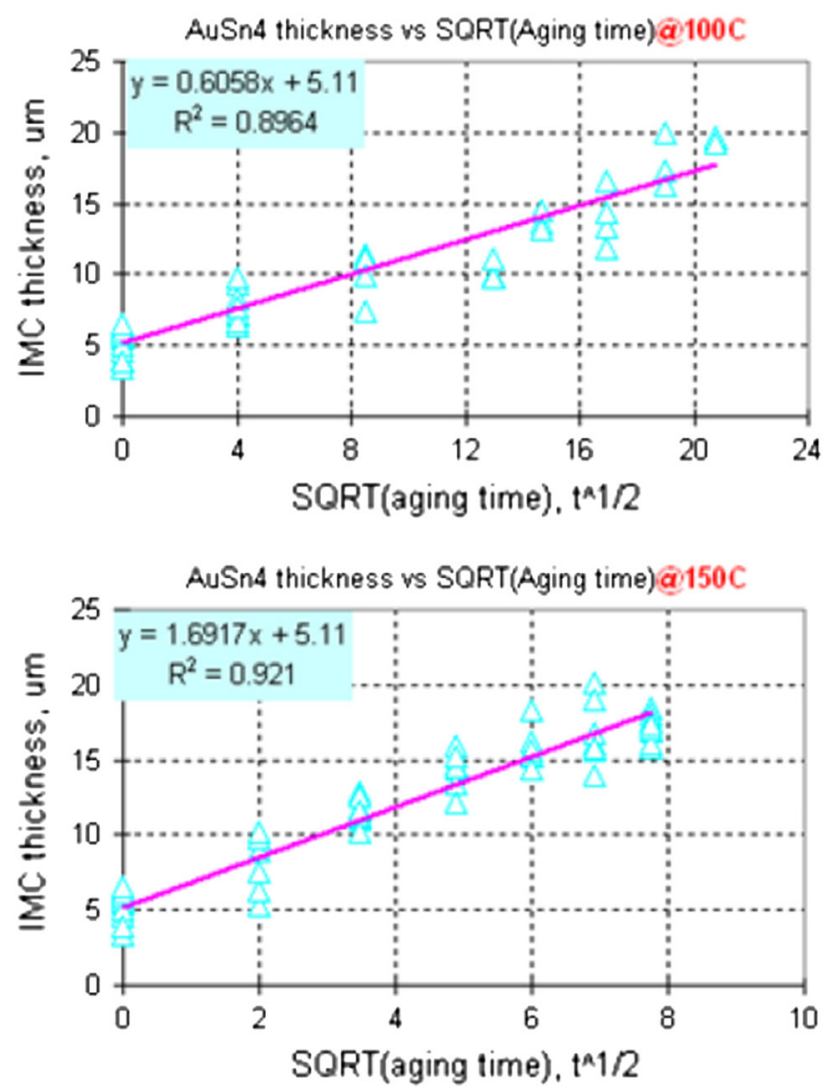

Fig. 7 Result of IMC growth at $100{ }^{\circ} \mathrm{C}$ and $150{ }^{\circ} \mathrm{C}$

Table 2 Comparison of the four teams above

\begin{tabular}{lll}
\hline $\begin{array}{l}\text { Prediction } \\
\text { methodology }\end{array}$ & $\begin{array}{l}\text { The thickness of AuSn4 } \\
\text { growth }(\mu \mathrm{m})\end{array}$ & $\begin{array}{l}\text { The solder } \\
\text { lifetime (years) }\end{array}$ \\
\hline Improved IMC & 20 & 14.46 \\
IMC & 23 & 10.06 \\
Electromigration & 22 & 13.39 \\
Thermal fatigue & 24 & 11.68
\end{tabular}

$\ln D_{0}-\ln D=(Q / R) \frac{1}{T}$

From Eq. (9), we can get $D$ at different aging time $t$, and from Eq. (11), we can get $D_{0}$ at every temperature $T$, so we can get $D$ at the working temperature; from Eq. (11), we can get solder joint lifetime.

To electromigration prediction, the parameters in the mean time-to-failure (MTTF) equation (Black's equations) were determined, and the equation is given as

$$
\mathrm{MTTF}=A J-2 \exp (Q / \mathrm{RT})
$$

where $A$ is the current density $\left(\mathrm{A} / \mathrm{cm}^{2}\right) ; J$ is a powerful factor; $Q$ is the activation energy $(\mathrm{J} / \mathrm{mol}) ; R$ is the universal gas constant $(8.314 \mathrm{~J} / \mathrm{mol} \mathrm{K}) ; T$ is the absolute temperature $(\mathrm{K})$
As a thermally activated process, the creep rate is increased exponentially with temperature. The effect of stress exponent $n$ may vary between 1 and over 15 , which reinforces the need to identify the dominant mechanisms in service and for accuracy in computing stress values. A generalized popular expression for creep is

$\dot{\varepsilon}_{m}=A \sigma^{n} g^{-p} \exp \left(\frac{-Q}{R T}\right)$

where $\dot{\varepsilon}_{m}$ is the minimum creep strain rate; $g$ is the grain size; $A, n$, and $p$ are constants; $Q$ is activation energy of dominant creep process.

Numerous expressions exist for the prediction of creep life although none is universally applicable. Among the most popular are those based upon the Monkman-Grant equation:

$\dot{\varepsilon}_{m} t_{r}=C$

where $\dot{\varepsilon}_{m}$ is the minimum creep strain rate; $t_{r}$ is the time to rupture; $C$ is a constant.

The matrix of acceleration high-temperature aging test is 150 and $100{ }^{\circ} \mathrm{C}$. Figures below are the prime results of each temperature. And its worth noting that the IMC growth rate is higher obviously with the increase of aging temperature. It is because that the Au atom diffuses quickly into Sn while the temperature becomes higher.

We can compare this result with these three methods. The comparison of the four teams is given in Table 2.

From the comparison made in Table 2, we can infer that IMC prediction methodology for solder is much better than others which show lower thickness of $\mathrm{AuSn}_{4}$ growth and more proper lifetime. This is because the high-temperature aging will destroy the head of solder joints to a certain extent, accelerate the growth of IMCs at the same time, and will also reduce the head solder joint life.

\section{Conclusions}

This paper has discussed the effect of IMC. After building an improved double correction IMC growth kinetic Mode, we also get some conclusion as below:

1. For AuSn alloy, $\mathrm{Ni}$ is better than $\mathrm{Ta}$ in moist and liability. $\mathrm{AuSn}_{4}$ 's lifespan is longer than that of other compounds such as $\mathrm{AuSn}_{2}$.

2. Complemented information and double corrections make the result clearer so that it can be promoted in picture and signal processing, which is the following step of writer's research. Moreover, because the results from complemented information and double correction are close to linearization result, in head production, 
linearization can bring down the failure rate and facilitate manual and machine operations.

3. The IMC growth kinetic theory is suitable with prediction IMC growth thickness and lifetime.

4. The diffusion constant under work condition $60^{\circ} \mathrm{C}$ is 0.015354 ; the solder lifetime $t$ is 14.46 years.

Acknowledgments This work was supported in part by the Erasmus Mundus Program under the supervision of the Directorate-General for Education and Culture (DG EAC of the European Commission) and EuropeAid Development and Cooperation (DG DEVCO). And it was also supported by National Natural Science Foundation of China under Grants 61173108, 61272147 and 60973032, and Hunan Provincial Natural Science Foundation of China under Grant 10JJ2045.

\section{References}

1. S. Wiese, M. Mueller et al. The creep behaviour and microstructure of ultra small solder joints. mechanical and multiphysics simulation and experiments in microelectronics and microsystems. 2011 12th. Int. Conf. on Thermal (2011)

2. A. Schubert, H. Walter, R. Dudek, B. Michel. Thermalmechanical properties and creep deformation of lead-containing and lead-free solders. 2001 international Symposium on Advanced Packaging Materials (2001)

3. K. Zhang, J. Yang et al. Research on creep properties of SnAgCuRE lead-free solders joints. IEEE. 2006 7th international conference on electronics packaging technology (2006)
4. X. Su, C. Yu, C. Qiang, Synthesis of a- $\mathrm{Fe}_{2} \mathrm{O}_{3}$ nanobelts and nanoflakes by thermal oxidation and study to their magnetic properties. Appl. Surf. Sci. 15, 258 (2012)

5. H. Li, D. Wei, S.N. Piramanayagam, Micromagnetic study of effect of tip-coating microstructure on the resolution of magnetic force microscopy. Phys. A 110, 7117 (2013)

6. M. Abtewa, G. Selvadurayb, Lead-free solders in microelectronics. Mater. Sci. Eng. 27, 95 (2000)

7. Z. Zhang, J. Li, H. Zhang et al., Thickness-dependent field emission from ZnTe films prepared by magnetron sputtering. J. Alloys. Compd. 18, 549 (2013)

8. L. Zhang, S.-X. Xue, Z.-G. Li et al., FePt-C granular thin film for heat-assisted magnetic recording (HAMR) media. Appl. Phys. A 116, 8343 (2014)

9. M. Kok, K. Yildiz, Oxidation parameters determination of $\mathrm{Cu}-$ $\mathrm{Al}-\mathrm{Ni}-\mathrm{Fe}$ shape-memory alloy at high temperatures. Appl. Phys. A 116, 8394 (2014)

10. Z.X. Zhang, X.J. Pan, T. Wang et al., Electrical properties of nanocrystalline GaN film prepared by magnetron sputtering. J. Alloys. Compd. 26, 467 (2009)

11. K. Zeng, K.N. Tu, Six cases of reliability study of Pb-free solder joints in electronic packaging technology. Mater. Sci. Eng., R 38, $256(2002)$

12. K.S. Kim, S.H. Huh, K. Suganuma, Effects of intermetallic compounds on properties of $\mathrm{Sn}-\mathrm{Ag}-\mathrm{Cu}$ lead-free soldered joints. J. Alloy. Compd. 32, 352 (2003)

13. K.S. Kim, S.H. Huh, K. Suganuma, Effects of intermetallic compounds on properties of $\mathrm{Sn}-\mathrm{Ag}-\mathrm{Cu}$ lead-free soldered joints. J. Alloy. Compd. 18, 352 (2003) 